\title{
INTERACTIVE IPTV SERVICES
}

\author{
Rastislav KOKOŠKA, Stanislav MARCHEVSKÝ \\ Department of Electronics and Multimedia Communications, Faculty of Electrical Engineering and Informatics, \\ Technical University of Košice, Park Komenského 13, 04200 Košice, Slovak Republic, \\ e-mail: rastko@pobox.sk, stanislav.marchevsky@tuke.sk
}

\begin{abstract}
The aim of this article is to point at the progress in interactive services, which are available in the area of a new generation television sets. The overview of MHP services, their qualities and ways of implementation are mapped. The offer of interactive television has got modern dimensions in the services of communication with the Internet, and its options to cohere the services like internet browser, Family Story, social net, You Tube, and other services. Modern interactive LED television set gives opportunities to implement a new generation of watching television signal, and own choice of interactivity.
\end{abstract}

Keywords: IPTV, MHP, digital television, IP internet protocol, MPEG-4, H.264, MHP (Multimedia Home Platform, VoD (Video on Demand), EPG (Electronic Programming Guide), PPV (Pay per View), VoIP (Voice over IP), live TV, IPTV (Internet protocol television)

\section{INTRODUCTION}

The article provides an overview of basic terms and qualities of television on the basis of IP (Internet Protocol TeleVision-IPTV), and its implementation requirements which characterize physical and implementation layers of the technology in use. The provided services offer above standard, and new approaches to multimedia and other demands of end clients, and the services providers as well. It shows the possibilities of MHP service, and application forms of utilization. It presents an overview of the interactivity options in modern interactive television sets.

IPTV describes transfer of television signals through IP connection. In spite of this IPTV doesn't mean watching videos from web only: "IPTV must not be replaced by simple video delivery through the IP net (including video) "[1]. Transfer of television broadcast through IP means that quality, functionality (e.g. protection of transfer content) applies to at least the same range as it is through other channels (terrestrial, satellite, cable).The IPTV technology is an interesting alternative of digital broadcasting.

The information transfer between provider and user is administered bidirectionally, what allows provider to find out the needs of all its users. The IPTV technology transfers television signal, but also other video information through a standard cableway. The only requirement is that the active appliances would support transfer of multicasts. IPTV covers both - live television broadcast, as well as a saved video, which is usually on demand (Video on Demand). Play from IPTV requires either a personal computer, or a set top box connected to a television set. Content of video is mostly compressed by either MPEG-2 or MPEG-4 codec, sent afterwards by MPEG transportation stream delivered through an IP multicast in case of live TV, or through IP unicast in case of Video on Demand. IP Multicast is a method in which information can be transferred once only, and received by numerous sets simultaneously. A newly issued (MPEG-4) H.264 codec more and more often replaces the old MPEG-2 codec.

\subsection{Services provided by IPTV}

\subsubsection{Services with linear subject matter}

Services with linear subject matter are characteristic by fixed broadcast scheme. Concrete contents and period of spread are decided by provider. Data streams watched by big groups of users are transmitted.

\subsubsection{Services with non-linear subject matter}

On the other hand, services with non-linear subject matter do not have fixed broadcast scheme. Beginning, length and contents are decided by each receiver individually. The result is individual data streams watched by a user who demanded them [3].

\section{INTREACTIVE IPTV SERVICES}

EPG (Electronic Programming Guide) digital text with additional information from sport, weather, news, etc., interactive computer games, interactive advertising, on-line shopping, e-mail, home banking, Internet access, etc. [5].

VoD (Video on Demand) Customer can order, at his operator through this service, a film or a sport record which he can watch at any time. VoD service demands a reverse channel (for example through telephone link, GPRS).

PPV (Pay per View) paid service, customer would watch a selected, otherwise coded program, film or sport event after having paid one single payment to a cable or satellite provider.

MHP (Multimedia Home Platform) a standard for multimedia services within digital television broadcast. It allows using, e.g. graphic teletext, interactive games or voting via remote control. MHP standard must be supported by digital set top box.

\subsection{Service - MHP}

Multimedia Home Platform defines generic interface between interactive digital applications and terminals (set top boxes), through which the applications are provided. It 
is also a standard for multimedia services within digital television broadcast. MHP platform is based on the following facts:

Data services, resp. MHP applications (also called Xlets) are delivered (created and provided) by a special technology applied on the transmission side of a television set equipped with DVB-T receiver.

MHP applications are processed on the side of DVB-T receiver by an implemented system software (middleware), which enables functioning of digital service applications, generally multimedia applications (and thus interactive as well), selected from corresponding multiplex of received signals. System software is mostly arranged as an independent one on operation system and hardware platform of DVB-T receiver, presented in Fig. 1.

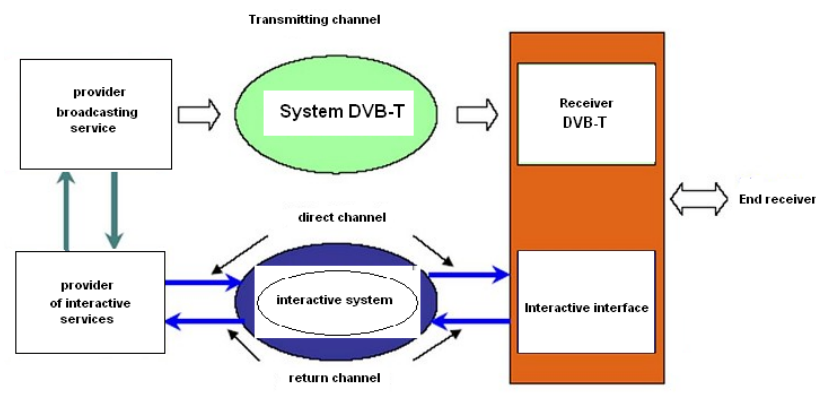

Fig. 1 Multimedia Home Platform

MHP presents: European standard of home multimedia platform, it enables a receiver to apply the applications transferred into it via digital broadcast, it is created with the application of the programming language Java (Xlet) specification, its constitution was preceded by solutions of different companies which were incompatible mutually (Open TV, Media Highway or Betanova) [4].

\subsection{MHP interactivity}

Local interactivity - without return channel. It is cyclic transmitted applications and data.

Full interactivity - with return channel.

Non-addressed interactivity - intended for all viewers, where is important that digital receiver was already equipped for the work with return channel with the help of modem or internet connection. Transmitted contents is the same for all viewers, but is modified on the basis of the information from the reverse channel.

Addressed interactivity - intended for one viewer.

Reverse data transmission - is provided with the help of ADSL, GSM, UMTS.

Home shopping/Home banking Shopping or procession of bank account through television set and its remote control.

Internet through DVB-T/RCT - Internet made available.

Interactive broadcast - Different types of games, chat with a program, influence on competitions and entertainment programs belong among this.

VoIP (Voice over IP) - Voice services.

Complementary services. On-line declassification of players' statistics at sport events, update of software through DVB-T, simple games, text information [4].

\section{MHP APPLICATIONS}

Data are cyclically transmitted together with television and radio programs. We can store applications and data into the memory of DVB-T receiver and run them locally.

The developing MHP levels are characterised as profiles, segmented into levels, while their reverse compatibility is preserved, i.e. the higher profile (level) platform enables to realize the services of lower profiles (levels).

Individual types of DVB-T receivers of MHP are specified by three currently defined profiles (e.g. interactive broadcast) completed by the number of specification (e.g...1.0.3), which refers to the number of specification in relevant norm ETSI.

Profile MHP 1 - Enhanced Broadcast - advanced broadcast - one way transmission of applications only, towards user, an option of local interactivity by remote control of the receiver, passive source of information with selective choice (superteletext, news ticker, HTML pages).

Profile MHP 2 - Interactive Broadcast - for interactive applications with the use of return channel via independent transmission appliance (e.g. telephone), when a return channel use is necessary for viewer's reaction (voting, quizzes, tests, games, e-shopping).

Profile MHP 3 - Internet Access - for Internet services, access to the Internet. Full interactivity including individual downloading of another data via return channel (e-mail, web browsing).

\subsection{Technological prospects of MHP}

From the point of view of MHP technological prospects, it is necessary to analyse technological impact of multimedia home platform (MHP). Accordingly, as a standard for interactive television, and simultaneously analyse see Fig. 2.

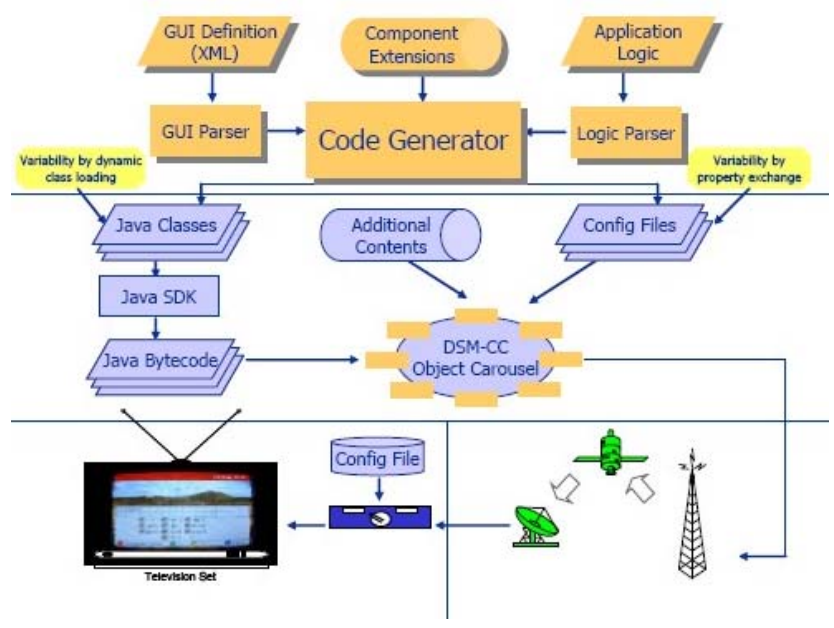

Fig. 2 Technological prospects of MHP [12]

Interactive advertising in MHP area is convergence in TV. At the same time, the Internet is basically the future with good prospects, depicted in Fig. 3 ShowProduct: The application prototype using potential for MHP product submission. 

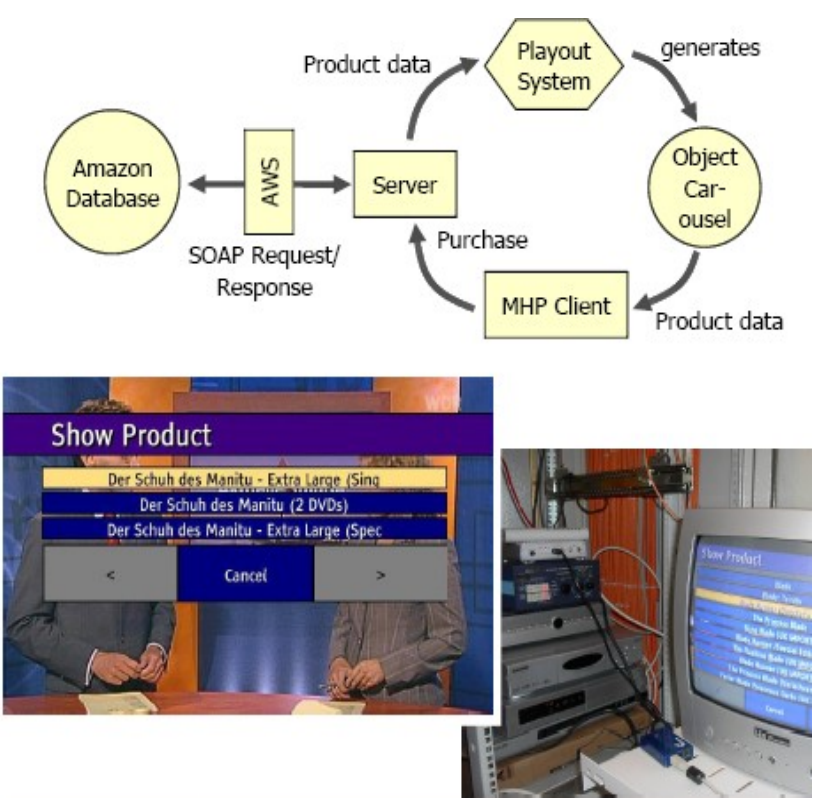

Fig. 3 Interactive advertising on MHP [12]

\subsection{Overview of MHP services in IPTV}

Television today is not only a source of information (and not much valued), alteration to leisure time - modern technologies enabled it to become an interactive centre of home entertainment and communication. Consumer today has also big demands. Classical watching television has been past for long, Smart TV and Smart Phone are common issue. That is why users are provided with a standard they are used to: Internet connection, control through Smart mobiles and external mice, share of contents with Smart and external appliances.

The function Smart TV uses wireless technology and facilitates watching in four areas. Net TV service will allow using a big amount of on line applications in television set: rent films, watch missed television programs, and use social nets. Shifting over channels or typing in texts is possible with the help of smart phone or tablet. Thanks to the function SimplyShare, on the ,television screen, it is possible to enjoy photos, music and video from computer or tablet. Program guide ensures smart download on USB. Illustrative process can be seen in Fig. 4 [6], [8].

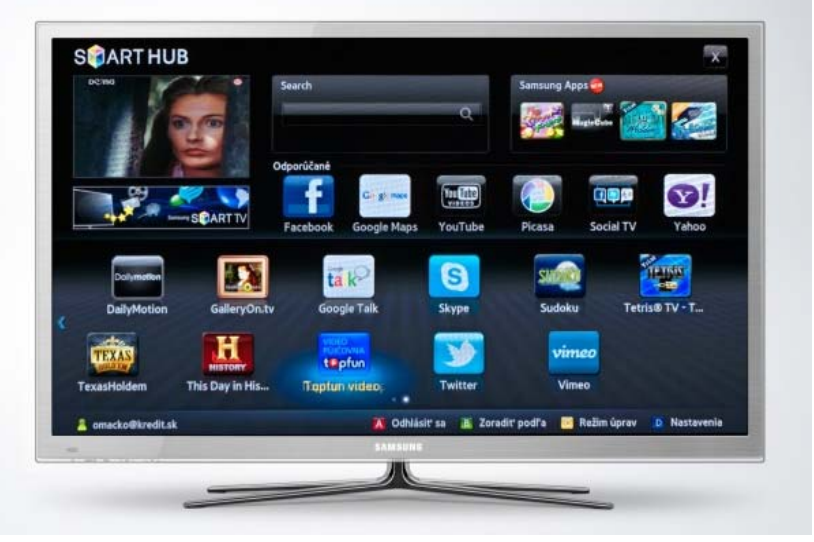

Fig. 4 Smart TV [7]
Television set producers use another benefit for TV set owners in a new application Stereo \& Video. The content of this application is the most interesting and latest information from the area of consumer electronic appliances. In case of Samsung, it is extension of local applications offer, as it is rent a video TopFun [9].

In January 2012, on an International exhibition of consumer electronics CES in Las Vegas, a new 'Samsung Smart Interaction' concept, which enables customers to communicate with their television sets through their voices, motions, or face identification, was introduced. It is an alteration to a remote control in a situation when its use is inappropriate, or comfortable. Thanks to a built-in high definition camera and two microphones in the flag line of new smart television sets, it is enough for an owner to greet his TV set to activate voice control. If, e.g. 'internet browser' is pronounced then, he will get access to the Internet where he can browse the search results. It is possible to turn volume up by voice or simple movement of hand [9].

\subsection{Interactivity in multimedia TV appliances}

Television set is no more a passive appliance, good as background of your dreaming only. TV set today is an active appliance on which you can watch what you are interested in, right when you want it (Smart Content). Moreover, it is an ideal appliance focused on communication in family. The latest models of smart television sets bring also voice or hand movement control, even more they recognize your face. One of the models is Samsung with an ultrathin $0.5 \mathrm{~cm}$ frame, built in adapter Wi-Fi, and special joystick in its rear part, see Fig. 5.

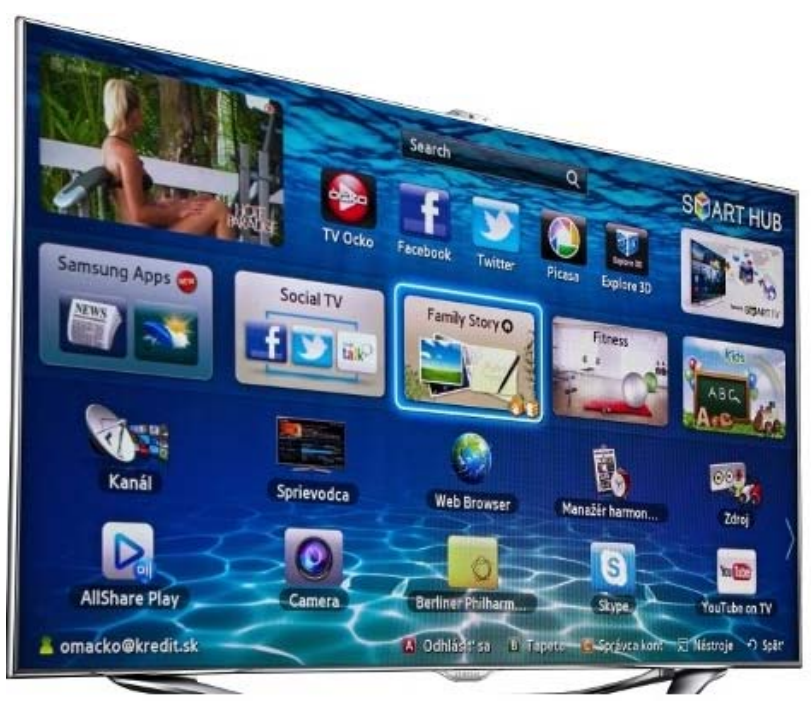

Fig. 5 Smart HUB TV [10]

Two core processors in today's television sets allow us to have in operation simultaneously television broadcast, active Skype, and everything is functioning at the same time. Television set is delivered with a classical remote control, alongside a smart remote control, and an adapter for external appliances connection. Ideal is use of mobile phone, which is operated by an operation system Android, or a tablet, with which the control is the fastest [10]. 


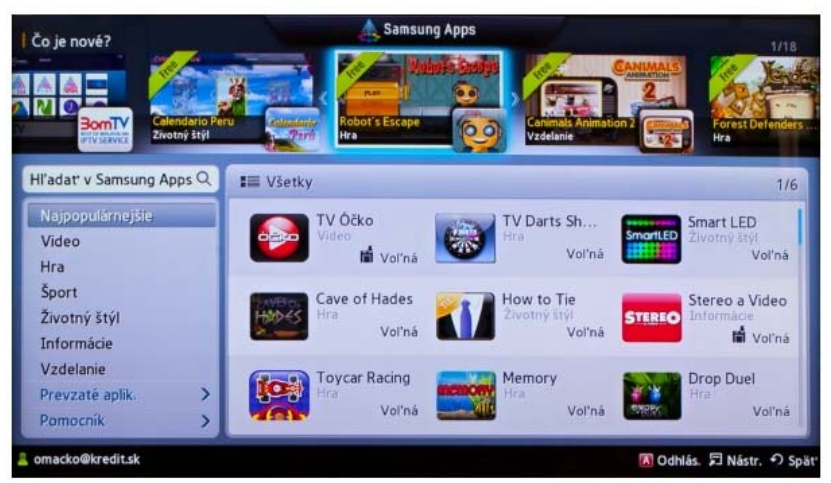

Fig. 6 Samsung apps [12]

\subsubsection{Voice control}

By now, it is not available in Slovak. Optional are, e.g. English (US or UK), German or Czech (and other languages). Anyway, the initial command to turn the television set voice control on is the word Hi TV (i.e. haj tí ví). Then, a menu enabling voice control of the most important commands appears - turn off TV, source, channel number, next/previous channel, turn up/down, turn the volume down, etc.

\subsubsection{Hand gesture control}

Something different is hand gesture control. You should be in a distance 1.5 to $4 \mathrm{~m}$, and start with slow movements of your hand with the palm open. Consequently, you will get a simple interface to change channels and volume. Commands are entered in the way that at a selected position the hand is closed into fist (Fig. 7).

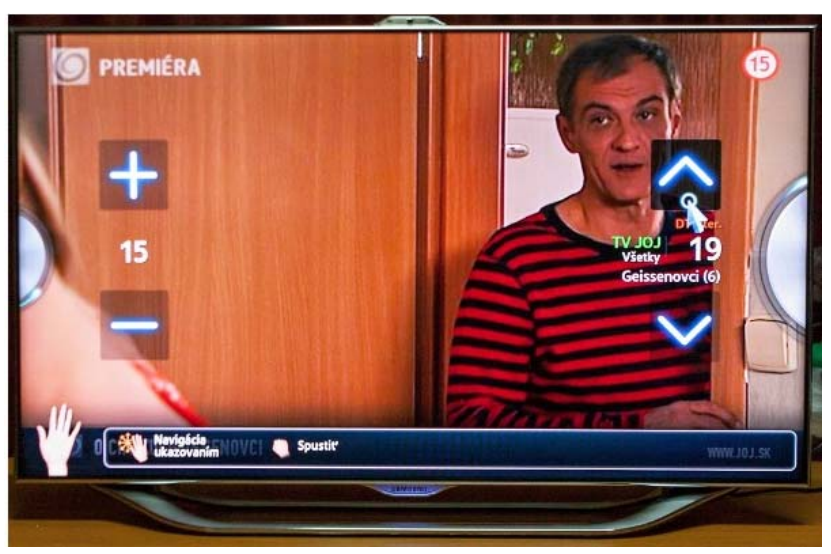

Fig. 7 Hand gesture control

\subsubsection{Family Story}

Another specialized brand services like Family Story, Fitness and Kids, first of their kind ever, will provide their users with even deeper television experience, and will help to keep close relationships with friends and family members [11].

The application Family Story is the answer on how a television set can interconnects family and acquaintances. We mean by this family interconnection worldwide, not only in front of one television set. To use this application, we recommend installing the application Family Story into an android telephone or tablet, and then transferring photos and experiences, so that the others can see them on television screen. Doing so, photos or videos are transferred into a cloud, and where from they are available to everybody who is invited into your group. An invitation to the group can be sent to different owners of the new television set, and all of them can share you experience (Fig. 8) [10].

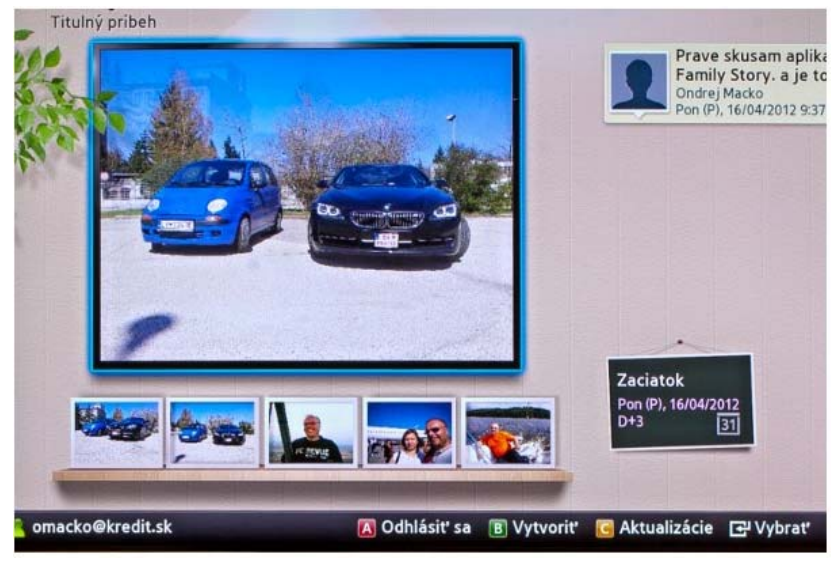

Fig. 8 Family Story

\subsubsection{Web Browser}

Smart Hub environment offers a lot of other applications, just to choose from and install. We liked very much the environment of Web Browser - this is exactly our image of the Internet in television set. We choose exactly the page we need, video play through Adobe Flash works, and it is perfectly controlled by a combination of hand movement and entering symbols by mobile phone. Also positively is assessed the application Skype, which works exactly like in computer, camera in the upper part of the television set provides our counterpart with a quality picture, as displayed in Fig.9 [10].

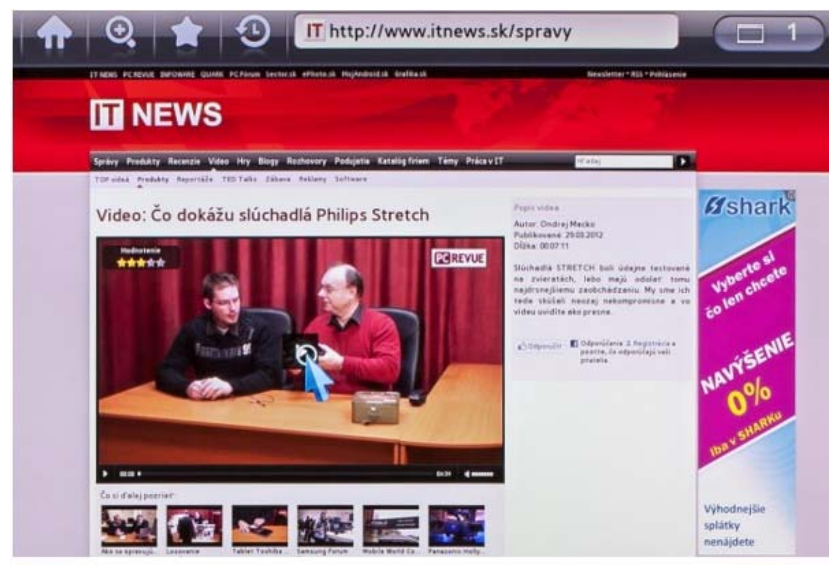

Fig. 9 Web Browser

Samsung Apps, the biggest world internet shop with applications for HDTV, by now offers more than 1400 applications, from the producers of the prominent trademarks like CNBC, ESPN, Google, Hulu, Netflix, MTV, NBA NBC Universal [11]. 


\section{CONCLUSIONS}

In the article, we wanted to point at new possibilities of interactive TV. MHP service belongs among interactive services. Its qualities, ways of implementation and individual profiles of MHP services were described. The services are possible to realize in Set-top box receivers and in current television sets as well.

Television sets of a new generation enable interactivity, and freedom of choice of your program, either by voice or gestures, resp. social net, Skype connection, and other different services. Interactive services in a new generation television sets are realized in the function Smart HUB. Thanks to USB connection, we can play films, watch photos through USB memory. TV set allows communication due to wireless Wi-Fi connection, e.g. with computer tablet, computer or telephone.

\section{REFERENCES}

[1] MINOLI, D.: IP Multicast with Applications to IPTV and Mobile DVB-H, Wiley-IEEE Press (2008), p. 2.

[2] SVOZILOVÁ, B.: Infrastructure for IPTV (transmission of TV programs in computer networks), Tomas Bata University in Zlin, Faculty of Applied Science. thesis 2009.

[3] HENS, F. J. - CABELlero, M. J. L.: TriplePlay, Building the converged network for IP, VoIP and IPTV. 1st edition. [s.1.]: Wiley, 2008, 416 p., ISBN 978-0470753675.

[4] SKŘIVÁNEK, L.: Digitální televise 2006/2007, 36ACS.

[5] HEJZLAR, M. et al.: Surfování na vlnách DVB-T, Sděl. technika 4/2005, pp. 16-17.

[6] http://mojdom.zoznam.sk/cl/10070/1307965/Novavizia-televizie

[7] http://www.techbox.sk/tv-video/c2692/samsung-maaplikaciu-na-sledovanie-tv-v-mobile-a-noveaplikacie-do-tv.html

[8] http://www.smetrendy.sk/28/Smart-TV-vkinoformate_311.aspx
[9] http://www.gamesite.sk/hw/novinky/9910-samsungrozsiruje-aplikacie-v-smart-tv-o-magazin-spotrebnejelektroniky-stereo-a-video.html, zdroj samsung.

[10] http://style.hnonline.sk/c3-55748780-kT0000_dinteligentny-televizor-dokaze-komunikovat-fontcolor-ff9900-foto-font

[11] http://siit.webnoviny.sk/tlacove-spravy/samsungtelevizor-super-oled-ma-dokona/176clanok.html? from $=$ section_article

[12] http://www.s3.uniduisburessen.de/?module= s3research\&category $=2$

Received June 26, 2012, accepted December 17, 2012

\section{BIOGRAPHIES}

Rastislav Kokoška was born on 5.11.1978 in Prešov. In 2003, he graduated (M.Sc.) from Technical University in Košice, Slovakia. He worked at Samsung Electronics Slovakia in Galanta as an engineer for testing circuit boards PBA. He is studying at doctoral studies in the external form at the Department of Electronics and Multimedia Communications, Faculty of Electrical Engineering and Computer Science at the Technical University in Košice. His scientific research focuses on modelling quality transmission of video data stream Internet TV on an unstable network.

Stanislav Marchevský received the M.Sc. in electrical engineering at the Faculty of Electrical Engineering, Czech Technical University in Prague, in 1976, and PhD. degree in radio electronics at the Technical University of Košice in 1985. Currently he is a Professor of Electronics and Multimedia Communications Department of Faculty of Electrical Engineering and Informatics of Technical University of Košice. His teaching interests include switching theory, digital television technology, and satellite communications. His research interests include image nonlinear filtering, neural networks, genetic algorithms, and multiuser detection, space-time communication, diversity communication over fading channel, and power and bandwidth efficient multiuser communications. 